\title{
Optimising automation of a manual enzyme-linked immunosorbent assay
}

\begin{abstract}
Authors:
Corena de Beer ${ }^{1}$

Monika Esser ${ }^{2}$

Wolfgang Preiser ${ }^{1}$

Affiliations:

${ }^{1}$ Department of Pathology

(Division of Medical

Virology), University of

Stellenbosch, South Africa

${ }^{2}$ Department of Pathology

(Immunology Unit),

University of Stellenbosch,

South Africa

\section{Correspondence to:}

Corena de Beer

email:

cdeb@sun.ac.za

\section{Postal address:}

Department of Pathology, University of Stellenbosch, PO Box 19063, Tygerberg 7505 , South Africa

Dates:

Received: 09 Dec. 2012

Accepted: 15 Aug. 2012

Published: 15 Oct. 2012

How to cite this article: De Beer C, Esser M, Preiser W. Optimising automation of a manual enzyme-linked immunosorbent assay. Afr J Lab Med. 2011;1(1), Art. \#15, 3 pages. http://dx.doi. org/10.4102/ajlm.v1i1.15
\end{abstract}

(C) 2012. The Authors.
Objective: Enzyme-linked immunosorbent assays (ELISAs) are widely used to quantify immunoglobulin levels induced by infection or vaccination. Compared to conventional manual assays, automated ELISA systems offer more accurate and reproducible results, faster turnaround times and cost effectiveness due to the use of multianalyte reagents.

Design: The VaccZyme ${ }^{\mathrm{TM}}$ Human Anti-Haemophilus influenzae type B (Hib) kit (MK016) from The Binding Site Company was optimised to be used on an automated BioRad PhD ${ }^{\mathrm{TM}}$ system in the Immunology Laboratory (National Health Laboratory Service) in Tygerberg, South Africa.

Methods: An automated ELISA system that uses individual well incubation was compared to a manual method that uses whole-plate incubation.

Results: Results were calculated from calibration curves constructed with each assay. Marked differences in calibration curves were observed for the two methods. The automated method produced lower-than-recommended optical density values and resulted in invalid calibration curves and diagnostic results. A comparison of the individual steps of the two methods showed a difference of 10 minutes per incubation cycle. All incubation steps of the automated method were subsequently increased from 30 minutes to 40 minutes. Several comparative assays were performed according to the amended protocol and all calibration curves obtained were valid. Calibrators and controls were also included as samples in different positions and orders on the plate and all results were valid.

Conclusion: Proper validation is vital before converting manual ELISA assays to automated or semi-automated methods.

\section{Introduction}

Quantitative analytical methods have advanced significantly since the development of the enzyme immunoassay (EIA) and enzyme-linked immunosorbent assay (ELISA) in 1971 by the groups of Perlmann and Engvall, and Schuurs and Van Weemen, respectively. ${ }^{1-3}$ Before this, the only method for performing immunoassays was the radioimmunoassay (RIA), which was first described by Yalow and Berson in $1960 .^{4}$

However, the RIA had several shortcomings, for example the potential health threat of radioactivity, short half-lives of radioisotopes, cumbersome radioactive waste disposal, expensive counting equipment, etc. ${ }^{3,5,6}$ An important shift from radioisotope-labelled liquid-phase assays to solidphase assays occurred in 1968. Miles and Hales ${ }^{7}$ developed an immuno-radiometric technique, which used radioactively labelled antibodies instead of labelled antigens for measuring insulin in human plasma. Plastic tubes were subsequently coated with the antigen or antibody to create a solid-phase or immunosorbent platform. ${ }^{8}$

Modern commercial ELISA/EIA kits use 96-well microtitre plates, where either an antigen or an antibody is noncovalently bound to a solid-phase support. These methods are widely employed by laboratories and manufacturing companies for microbiological, virological and other serological diagnostic tests, validation of assays and general quality control. Although automated pipetting devices have been used for more than two decades, the high cost associated with the technique remains a major limiting factor in developing countries and smaller laboratories. ${ }^{3}$

\section{Materials and methods}

The Immunology Unit of the National Health Laboratory Service (NHLS) in Tygerberg, South Africa, uses ELISAs for serological quantification of antibody levels. Before installation of the BioRad $\mathrm{PhD}^{\mathrm{TM}}$ system, all assays had been performed manually. The system performs sample dilution, dispenses patient samples and reagents into the microplate, and performs temperaturespecific incubation and washing according to pre-defined protocols. 


\section{Automation of the MK016 enzyme-linked immunosorbent assay}

The 96-well microtitre plate included in the VaccZyme ${ }^{\mathrm{TM}}$ Human Anti-Haemophilus influenzae type B (Hib) kit (MK016) from The Binding Site Company (Birmingham, United Kingdom) is precoated with the Hib capsular polysaccharide antigen conjugated to human serum albumin. In addition to controls and other reagents, the kit also contains five calibrators $(0.1 \mathrm{mg} / \mathrm{L}-9.0 \mathrm{mg} / \mathrm{L})$ to construct a five-point calibration curve. Concentration (logarithmic scale) is plotted against optical density (linear scale) to produce the calibration curve. The quantification range for anti-Hib antibody concentration is $0.11 \mathrm{mg} / \mathrm{L}-9.0 \mathrm{mg} / \mathrm{L} .{ }^{9}$

Prediluted samples and controls were pipetted into the plate and incubated for 30 minutes. Unbound proteins were removed by a wash step before addition of conjugate (purified peroxidase-labelled rabbit anti-human $\gamma$-chain-specific immunoglobulin G). After a further 30 minutes of incubation, another wash step was applied to remove all excess conjugate. Substrate $\left(3.3^{\prime}, 5.5^{\prime}\right.$ tetramethylbenzidine) was then added, which induced a colour change (from the characteristic serum colour to blue) over 30 minutes. Phosphoric acid was then added to stop colour development. The optical density (OD) was measured spectrophotometrically at $450 \mathrm{~nm}$ and the intensity of the final colour is proportional to the concentration of antibody present in the sample.

A list of assays that are validated on the $\mathrm{PhD}^{\mathrm{TM}}$ system is available from BioRad (www.bio-rad.com; $\mathrm{PhD}^{\mathrm{TM}}$ Validated Assay List).

\section{Results}

Analyses with ELISA kits from the BioRad list produced valid results in our laboratory and these methods were automated without any problems. However, when performing the nonvalidated MK016 assay on the $\mathrm{PhD}^{\mathrm{TM}}$ system, the calibrators did not produce the required OD values recommended by the quality control sheet included in the kit (Figure 1).

The highest calibrator reached an OD of only $1.417 \pm 0.245$ (range 1.252-1.813) instead of 2.500 as specified on the quality control certificate. Although the lower calibrators were associated with smaller margins of error, they showed a similar trend. All results calculated from this calibration curve were therefore too low and hence invalid.

Comparison of the individual steps of the automated and manual methods identified a difference of 10 minutes in all incubation periods. The $\mathrm{PhD}^{\mathrm{TM}}$ system times incubation for each well individually and proceeds to the next step only once the exact incubation time has been reached for that specific well. However, timing of manual assays usually starts only after reagents have been added to the last well of the plate; i.e. well incubation is timed rather than plate incubation.

In an effort to address this difference, all incubation steps were increased from 30 minutes to 40 minutes on the $\mathrm{PhD}^{\mathrm{TM}}$ system. The duration of the washing steps of the two methods was very similar and therefore not regarded as contributing to the discrepant results. The duration of the washing steps was therefore left unchanged.

A total of 16 calibration curves were subsequently generated from the $\mathrm{PhD}^{\mathrm{TM}}$ system to validate the adjusted protocol. All the OD values obtained produced acceptable calibration curves (Figure 2) and the mean OD value for the highest calibrator reached $2.295 \pm 0.171$ (median $=2.405$; range $=1.934-2.553)$. The recommended values for the high and low controls are $2.4 \mathrm{mg} / \mathrm{L}-3.6 \mathrm{mg} / \mathrm{L}$ and $<0.35 \mathrm{mg} / \mathrm{L}$, respectively. The high and low controls as used on the $\mathrm{PhD}^{\mathrm{TM}}$ system produced results of $2.538 \pm 0.094 \mathrm{mg} / \mathrm{L}$ and $<0.35 \mathrm{mg} / \mathrm{L}$, respectively.

To confirm our findings, calibrators and controls were included in different positions and orders on the plate. Values obtained for these tests were within $5 \%$ of the required ranges, which suggested that the amended protocol had a uniform effect on all individual wells of the plate (data not shown).

\section{Discussion}

Automated systems, such as the BioRad $\mathrm{PhD}^{\mathrm{TM}}$ instrument, are extremely useful and accurate in assessing immune

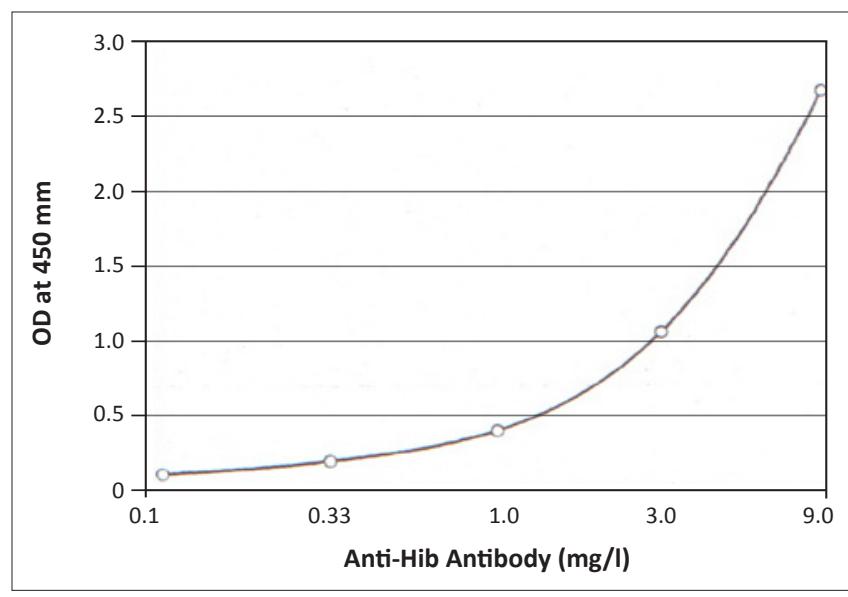

FIGURE 1: VaccZyme ${ }^{\mathrm{TM}}$ Anti-Hib Enzyme-linked immunosorbent assays calibration curve as provided on the quality control sheet. ${ }^{9}$

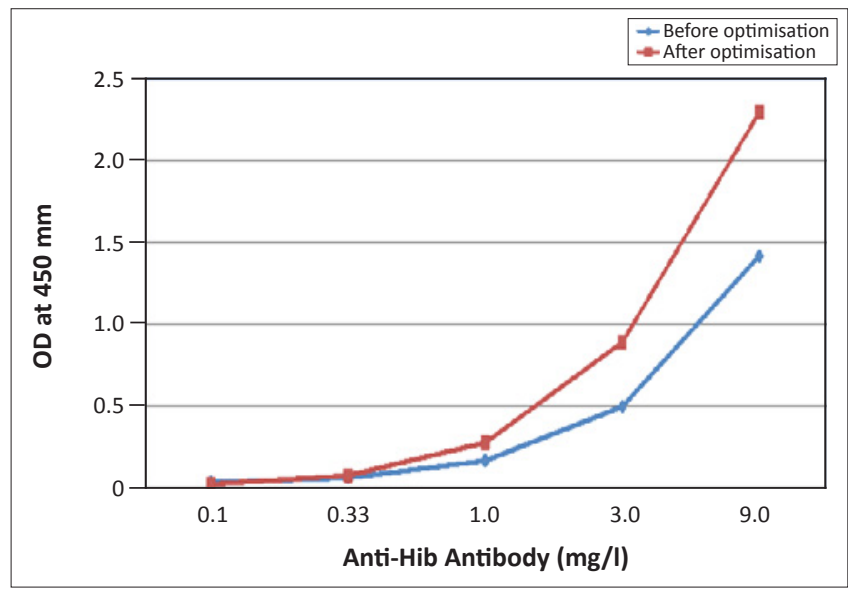

FIGURE 2: VaccZyme ${ }^{\mathrm{TM}}$ Anti-Hib enzyme-linked immunosorbent assay calibration curves before and after optimisation. 
responses to specific antigens following disease or vaccination. The major advantages of automation or semi-automation include the use of volumes as low as $1 \mu \mathrm{L}$, increased accuracy and reproducibility of results, better use of expensive skilled labour, faster overall laboratory turnaround time, ability to perform multiple assays simultaneously and cost effectiveness due to use of multianalyte reagents. Use of an automated system also eliminates pipette volume variation and handling errors.

Accurate, reproducible and reliable laboratory results are crucial for patient management and care, such as initiating treatment in patients with possible immunodeficiency and revaccination of children with insufficient protection following routine childhood vaccination. It is furthermore important for evaluation of study cohort results or establishing reference ranges for specific populations or age groups.

This study emphasises the importance of optimisation and validation whenever changing protocols or reagents in order to produce valid and accurate results. In the case of the MK016 assay it was not possible to transfer the protocol established for the manual method to the automated system without modification. After troubleshooting all the individual steps of both methods, a methodological difference was identified and addressed. The modified protocol was scrutinised by repeated measurements of samples of known concentration in different assays and plate positions before amending the existing protocol.

\section{Acknowledgements}

We would like to thank Allere Healthcare (Pty) Ltd (Bedfordview, South Africa) for donating test kits for optimisation.

\section{Competing interests}

The authors declare that they have no financial or personal relationship(s) which may have inappropriately influenced them in writing this paper.

\section{Authors' contributions}

C.d.B. was the project leader and responsible for experimental and project design, as well as performing the experiments and writing the manuscript. M.E. was the head of the laboratory where the experiments were conducted and W.P. provided valuable input into the final manuscript.

\section{References}

1. Engvall E, Perlman P. Enzyme-linked immunosorbent assay (ELISA). Quantitative assay of immunoglobulin G. Immunochemistry. 1971;8(9):871-874. http://dx.doi. org/10.1016/0019-2791(71)90454-X

2. Van Weemen BK, Schuurs AH. Immunoassay using antigen-enzyme conjugates. FEBS Lett. 1971;15(3):232-236. http://dx.doi.org/10.1016/00145793(71)80319-8

3. Lequin R. Enzyme immunoassay (EIA)/enzyme-linked immunosorbent assay (ELISA). Clin Chem. 2005;51(12):2415-2418. http://dx.doi.org/10.1373/ clinchem.2005.051532

4. Yalow R, Berson S. Immunoassay of endogenous plasma insulin in man. J Clin Invest 1960;39(7):1157-1175. http://dx.doi.org/10.1172/JCI104130

5. Gosling JP. A decade of development in immunoassay methodology. Clin Chem. 1990;36(8):1408-1427.

6. Engvall E. The ELISA, Enzyme-linked immunosorbent assay. Clin Chem. 2010;56(2):319-320. http://dx.doi.org/10.1373/clinchem.2009.127803

7. Miles LEM, Hales CN. Labelled antibodies and immunological assay systems. Nature 1968;219:186-189. http://dx.doi.org/10.1038/219186a0

8. Engvall E, Jonsson K, Perlmann P. Enzyme-linked immunosorbent assay, ELISA. II. Quantitative assay of protein antigen, immunoglobulin G, by means of enzymelabeled antigen and antibody-coated tubes. Biochem Biophys Acta 1971;251:427434. http://dx.doi.org/10.1016/0005-2795(71)90132-2

9. Package Insert, 24 May 2006. VaccZyme ${ }^{\mathrm{TM}}$ Human Anti Haemophilus influenzae type b (Hib) Enzyme Immunoassay Kit MK016. The Binding Site, Birmingham, UK. 